Argonne

\title{
Application of an Erosion Wear Model to Predict Wear of Hammer Milling Components
}

Applied Materials Division 


\begin{abstract}
About Argonne National Laboratory
Argonne is a U.S. Department of Energy laboratory managed by UChicago Argonne, LLC under contract DE-AC02-06CH11357. The Laboratory's main facility is outside Chicago, at 9700 South Cass Avenue, Lemont, Illinois 60439. For information about Argonne and its pioneering science and technology programs, see www.anl.gov.
\end{abstract}

\title{
DOCUMENT AVAILABILITY
}

Online Access: U.S. Department of Energy (DOE) reports produced after 1991 and a growing number of pre-1991 documents are available free at OSTI.GOV (http://www.osti.gov/),

a service of the US Dept. of Energy's Office of Scientific and Technical Information.

Reports not in digital format may be purchased by the public from the National Technical Information Service (NTIS):

U.S. Department of Commerce

National Technical Information Service

5301 Shawnee Road

Alexandria, VA 22312

www.ntis.gov

Phone: (800) 553-NTIS (6847) or (703) 605-6000

Fax: (703) 605-6900

Email: orders@ntis.gov

Reports not in digital format are available to DOE and DOE contractors from the Office of Scientific and Technical Information (OSTI):

U.S. Department of Energy

Office of Scientific and Technical Information

P.O. Box 62

Oak Ridge, TN 37831-0062

www.osti.gov

Phone: (865) 576-8401

Fax: (865) 576-5728

Email: reports@osti.gov

\section{Disclaimer}

This report was prepared as an account of work sponsored by an agency of the United States Government. Neither the United States Government nor any agency thereof, nor UChicago Argonne, LLC, nor any of their employees or officers, makes any warranty, express or implied, or assumes any legal liability or responsibility for the accuracy, completeness, or usefulness of any information, apparatus, product, or process disclosed, or represents that its use would not infringe privately owned rights. Reference herein to any specific commercial product, process, or service by trade name, trademark, manufacturer, or otherwise, does not necessarily constitute or imply its endorsement, recommendation, or favoring by the United States Government or any agency thereof. The views and opinions of document authors expressed herein do not necessarily state or reflect those of the United States Covernment or any agency thereof, Argonne National Laboratory, or UChicago Argonne, LLC. 


\section{Application of an Erosion Wear Model to Predict Wear of Hammer Milling Components}

by

George Fenske and Oyelayo Ajayi

Applied Materials Division, Argonne National Laboratory

September 30, 2020 



\section{CONTENTS}

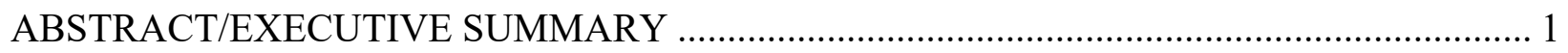

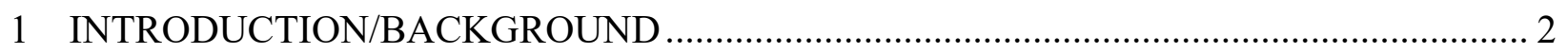

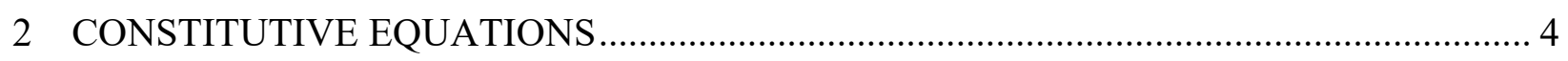

3 VALIDATION OF WEAR MODEL AGAINST HAMMER MILL RESULTS ...................... 6

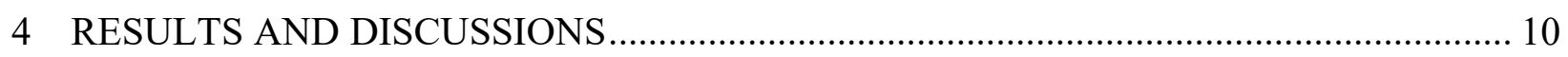

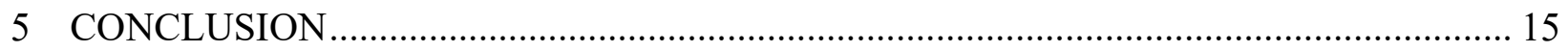

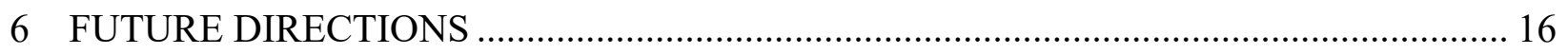

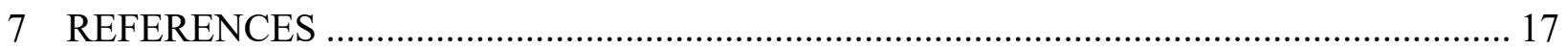

\section{FIGURES}

1 Unit operations used during pretreatment of feedstock prior to low-temperature conversion of corn stover (courtesy National Renewable Energy Laboratory)........................ 2

2 Wear of plug screw feeder components (top) and stage-1 hammer mills (bottom) (courtesy M. Tucker, National Renewable Energy Laboratory)................................................ 3

3 Illustration of parallel and perpendicular components of particle impingement associated with 'cutting' and 'deformation' mechanisms [9] ...Error! Bookmark not defined.

4 Illustration of QbD process for modeling component wear as functions of feedstock CMAs, hammer CMAs, and unit processing parameters, CPPs to wear (CQAs)

5 Illustration of the Vermeer Stage 1 hammer mill used to grind bales into loose feedstock. 7

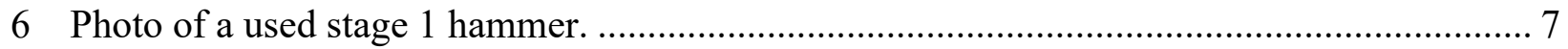

7 Schematic of incremental wear volume on a stage 1 hammer............................................. 8

8 Radial distribution of inorganic particle density for a feed rate of $1 \mathrm{~kg} / \mathrm{sec}$ and ash content of $5 \%$.

9 Amount of material eroded tangential to hammer face - using process parameters in Table 2 (note the number of revolutions corresponds to 24 hours of operation).

10 Comparison of predicted shape with actual shape of a worn. Yellow line (right) illustrates projected shape for the exponential particle density distribution. 


\section{TABLES}

1 Case 1-6 Density Assumptions ................................................................................ 11

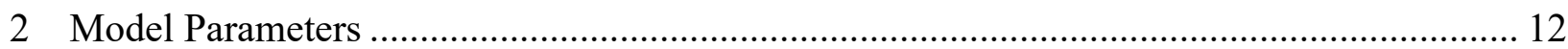

3 Effect of Hammer Face Angle on Hammer Face Recession ............................................ 13

4 Effect of Hammer Rotational Speed on Hammer Face Recession ..................................... 13

5 Predicted Hammer Recession, $\Delta \perp$ (m), for Different Material Property Combinations......... 14 


\begin{abstract}
EXECUTIVE SUMMARY
A workable analytical erosion model that relates critical hammermill process parameters (hammermill geometry and rotational speed) to critical material attributes of inorganic mineral species in feedstock (density, size, and aspect ratio) and substrate (hardness, toughness, and fatigue ductility) was applied to model wear (more specifically, change in the shape of hammers) in hammer milling operations. Results of the model were compared to experimental observations of the shape of hammers used in the INL Stage 1 Vermeer hammermill. Results showed good agreement between predicted and measured shape of the hammer, and that a quality-by-design $(\mathrm{QbD})$ approach can be developed to predict component reliability based on scientific engineering principles in lieu of trial-and-error approaches.
\end{abstract}




\section{INTRODUCTION/BACKGROUND}

There is considerable interest worldwide in developing processes to transform nonfood sources of biomass into bioproducts, biofuels, and bioenergy. The U.S. Department of Energy's Bioenergy Technologies Office supports activities to develop innovative technologies for converting biomass into usable products, fuels, and energy, including activities on Feedstock Supply \& Logistics (FSL), Agal Biofuels, Sustainability, Analysis, and Conversion Technologies [1]. Recognizing the importance of pretreatment of biomass feedstocks on the development of value-added products [2-4], the Feedstock Conversion Interface Consortium (FCIC;

https://fcic.inl.gov) develops first principles-based knowledge and tools to understand the effects of biomass properties and process variability on pretreatment operations.

Pretreatment of biomass feedstocks is an essential step in changing the structure of lignocellulosic fractions into a state that responds to enzymatic hydrolysis. Pretreatment processes involve a number of unit operations requiring milling, grinding, cutting, and mechanical transport of feedstock from one stage to another. Because of the nature of mechanical interactions between feedstock (and ash) and surfaces of materials of construction, wear can occur and limit the reliability and functionality/performance of critical unit operations.

Figure 1 illustrates the different unit operations associated with preprocessing of corn stover for low-temperature conversion to ethanol. Virtually all the operations are potential sites for wear and degradation.

In the figure, the operations highlighted in blue are units on which significant wear has been observed. These units include grinders (first- and second-stage hammer mills) and plug screw feeders used to form a pressure plug between the atmospheric operations and the high-pressure zone.

Examples [5] of wear observed in grinding and plug screw feeding are shown in the highlighted regions in Figure 2 [6]. The flutes of the screw for the worn screw feeder are visibly smaller, and the leading edge for the hammer is rounded. Analysis of the worn

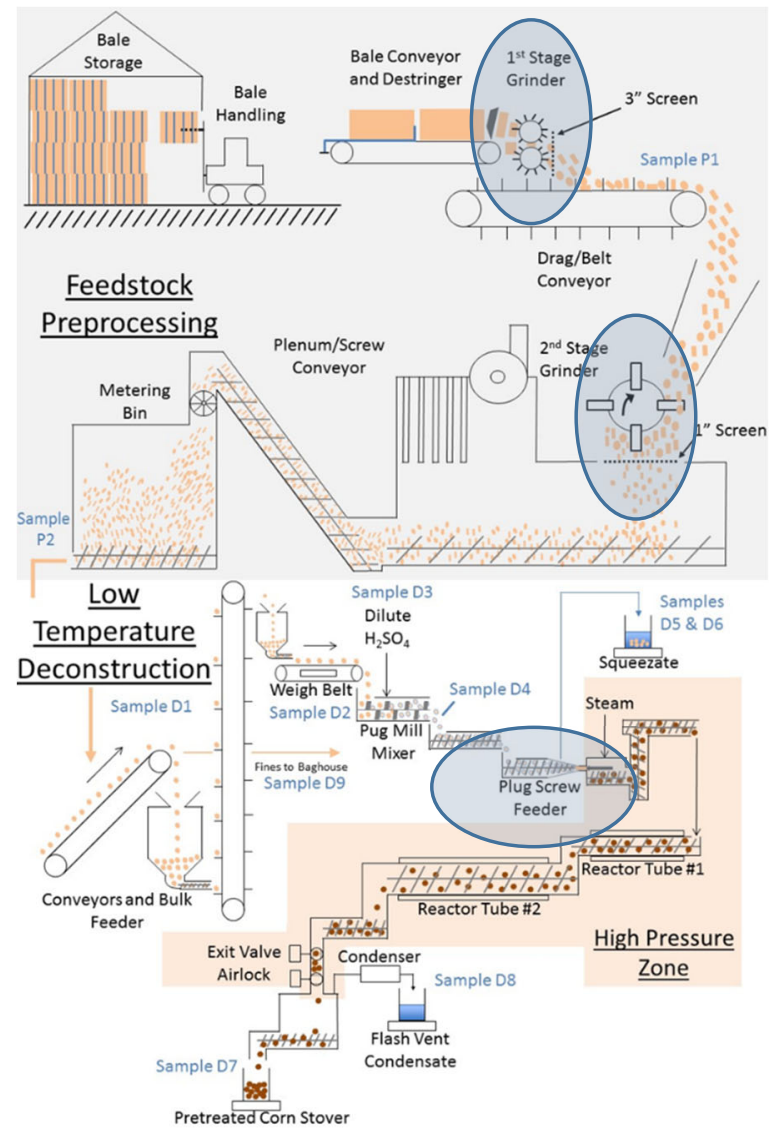

FIGURE 1 Unit operations used during pretreatment of feedstock prior to lowtemperature conversion of corn stover (courtesy: Erik Kuhn - National Renewable Energy Laboratory) 
surfaces $[7,8]$ suggests particle abrasion/erosion and micropolishing are major causes of the observed wear.

Abrasion and erosion are complex phenomena that are dependent on the nature of the material (biomass feedstock and entrained ash) causing the wear and on the nature of the material undergoing wear (material and mechanical properties of materials of construction) and on operating /process parameters (speed, temperature, loads, and so on).

The current approach to addressing wear commonly starts by using components designed for other applications (e.g., paper and pulp) that treat feedstock with significantly different attributes or processing parameters or Edisonian trial-and-error testing of materials.

Both approaches have merit; however, an ability to
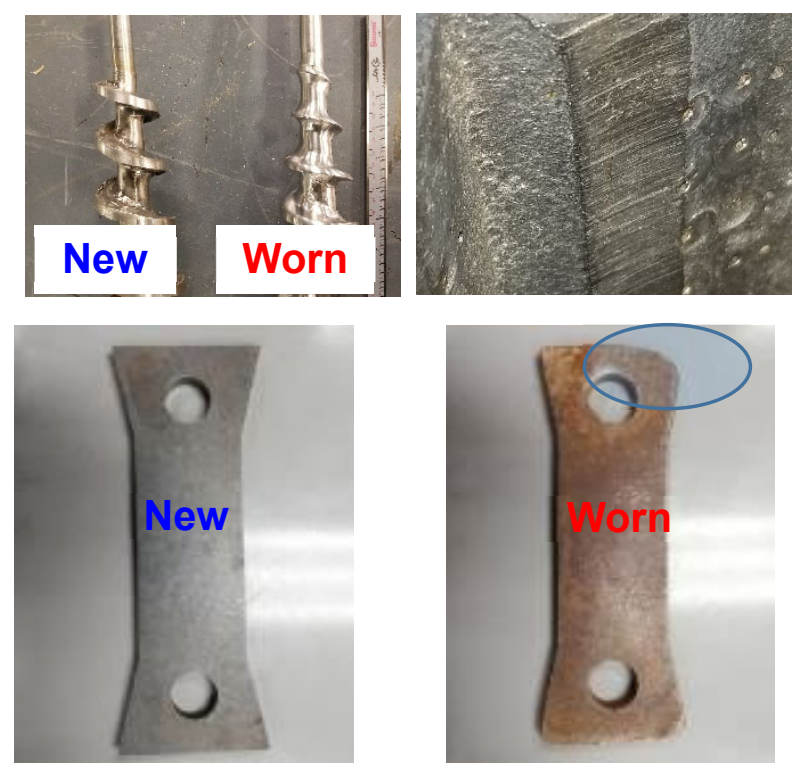

FIGURE 2 Wear of plug screw feeder components (top) and stage-1 hammer mills (bottom) (courtesy M. Tucker, National Renewable Energy Laboratory) predict wear based on critical material attributes and critical process parameters has great potential for more effective design and engineering of unit operation processes.

The results presented in this report describe efforts to apply a mechanistic model of wear based on physical mechanisms involved in abrasion and erosion processes to predict wear of the stage 1 hammers used in the Process Development Unit (PDU) at the INL Biomass Feedstock National User Facility (https://bfnuf.inl.gov/SitePages/Process\%20Development\%20Unit.aspx). Previous results provided details of the erosion wear model [5] originally developed by Ben-Ami et al. [9], and validation of the model against bench simulation studies [10] performed by INL using their Accelerated Wear Test (AWT) rig. The current work uses the same Quality-byDesign (QbD) approach used to validate the wear model against the INL bench simulation [10], with appropriate changes to the process parameters due to different test configurations (grit blasting vs hammer milling). 


\section{CONSTITUTIVE EQUATIONS}

The study of wear of components used in comminution of minerals and biomass is not new, and the fundamental mechanisms are well known. General reviews of solid particle erosion and abrasive wear mechanisms are referenced in [10]. They form the basis for a semi-mechanistic wear model developed by Ben-Ami [9] that relates the volumetric wear volume (volume of material worn per incident particle, $\Delta \mathrm{Q}_{\mathrm{T}}$, due to an impact of a particle with the surface to cutting mechanisms (motion parallel to the surface, $\Delta \mathrm{Q}_{\mathrm{C}}$ ) and deformation mechanisms (motion perpendicular to the surface, $\Delta \mathrm{Q}_{\mathrm{D}}$ ) (see Figure 3).

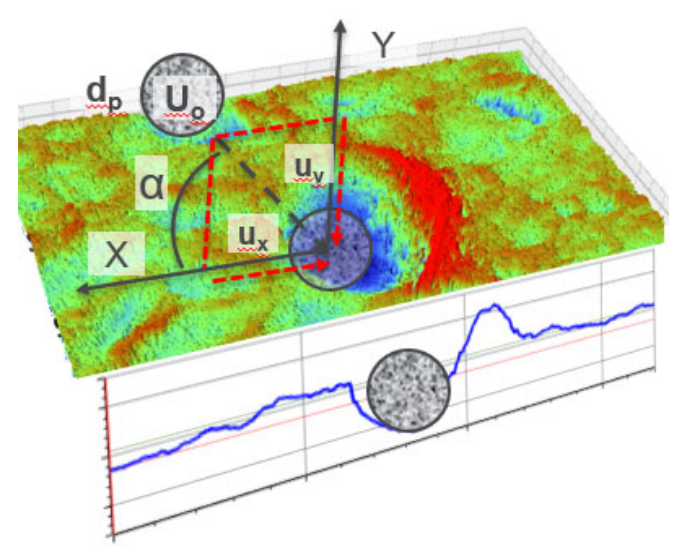

Figure 3: Illustration of parallel and perpendicular components of particle impingement associated with 'cutting' and 'deformation' mechanisms [5]

$$
\Delta Q_{T}=\Delta Q_{D}+\Delta Q_{C}
$$

where

$$
\begin{aligned}
& \Delta Q_{T}=\text { the total volume lost due to particle impact } \\
& \Delta Q_{D}=\text { the volume lost to repeated deformation events arising from the normal component } \\
& \quad \text { of a particle impacting a surface, and } \\
& \Delta Q_{C}=\text { the cutting component arising from the horizontal motion of a particle. }
\end{aligned}
$$

Constitutive relations were developed to relate $\Delta Q_{D}$ and $\Delta Q_{C}$ to feedstock properties (density of incident particles, particle size distribution, and ash content ${ }^{1}$ ), material (hammer) properties (hardness, toughness, and fatigue ductility), and process parameters (speed and angle of impingement). The models take into account the following parameters:

${ }^{1}$ Ideally we prefer to use a particle content, number of inorganic particles of a given size per unit mass. In lieu of this, we use the ash content, percentage of inorganic ash after firing at $750^{\circ} \mathrm{C}$. 


$\begin{array}{ll}H & \text { target material hardness, } \mathrm{Pa} \\ R & \text { target material fracture toughness, } \mathrm{J} / \mathrm{m}^{2} \\ \varepsilon f & \text { fatigue ductility coefficient } \\ b & \text { fatigue ductility exponent } \\ d & \text { particle diameter, } \mathrm{m} \\ \eta & \text { particle shape factor }(0-1) \\ \rho & \text { density, } \mathrm{kg} / \mathrm{m}^{3} \\ \alpha & \text { particle impingement angle rad } \\ U & \text { particle impact velocity, } \mathrm{m} / \mathrm{s} \\ f & \text { model empirical exponent } \\ C_{C} & \text { semi-empirical model coefficient } \\ C_{D} & \text { semi-empirical model coefficient }\end{array}$

Ploughing and fracture mechanisms were included in the model for cutting wear, $\Delta Q_{C}$, which yielded the following relationship for wear associated with the horizontal portion of particle velocity:

$$
\frac{\Delta Q_{C}}{m_{p}}=C_{c}(1+f)\left[1-\exp \left(-200 \alpha^{2}\right)\right] \frac{\left(\frac{\rho_{p} d_{p}^{2}}{\eta}\right)^{(1-f) / 2}}{H^{\left(\frac{1+f}{2}\right)} R^{(1-f)}} U_{0}^{3-f} \cos ^{2}(\alpha) \sin ^{1-f}(\alpha)
$$

The deformation wear related to the normal component of particle impact assumes that deformation erosion is caused by crack propagation arising from repeated plastic deformation and incorporates a fatigue fracture model (Coffin-Mason) criteria for low-cycle fatigue. The deformation wear rate (per unit particle mass) is given as:

$$
\frac{\Delta Q_{D}}{m_{p}}=C_{D} \frac{\rho_{p}^{1 / 4 b}}{\eta^{3 / 4 b} \varepsilon_{f}^{1 / b} H^{(1+1 / 4 b)}}\left[U_{0} \sin (\alpha)\right]^{2+1 / 2 b}
$$

The coefficients $C_{D}$ and $f$ depend on material hardness and toughness, while $C_{C}$ is independent of hardness, toughness, or fatigue parameters. 


\section{VALIDATION OF WEAR MODEL AGAINST HAMMER MILL RESULTS}

A QbD approach was adapted to identify cause-and-effect relationships between feedstock and hammer material properties/attributes (MAs), unit operational process parameters (PPs), and quality attributes (QAs) in an overall process flow diagram of a preprocessing stream.

The output (QA) of a unit operation serves as an input (MA) of the next operation. Figure 4 shows the QbD flow diagram for the stage 1 hammer mill. The analysis follows this approach and involves detailed analysis of feedstock MAs, hammer MAs, and processing PPs to predict hammer wear QAs. The QbD process utilizes constitutive models developed by Ben Ami to calculate the QA (wear) as functions of the MAs and PPs (eqs. 1-3).

Application of the QbD approach to validate the model against a series of INL accelerated wear simulation (corn/grit blaster) studies using corn stover and pine feedstock can be found in reference 10 where detailed information on feedstock and hammer material attributes (MAs) and process parameters for the AWT simulation technique is presented.

The same QbD approach used (Figure 4) to validate the erosion model against test-coupon wear is the same $\mathrm{QbD}$ approach used to validate the model against hammer mill wear, with the exception that a different set of process parameters were developed to determine critical process parameters associated with the actual hammer mill operation.

An illustration of the working components of the INL Stage 1 Vermeer bale grinder is depicted in Figure 5. For the tests under consideration, half-ton bales of corn stover were fed horizontally into the hammer zone that consisted of 6 rows of hammers (16 hammers per row) for a total of 96 hammers. The hammers rotated at speeds ranging from approximately 600 to $1200 \mathrm{rpm}$. The diameter of the drum is approximately $1 \mathrm{~m}$, with a length of approximately $1.5 \mathrm{~m}$. The bales (approximately $1 / 2$ ton each) are assumed to be $1.5 \mathrm{~m}$ in length $x 0.5 \mathrm{~m}$ tall $\mathrm{x} 0.75 \mathrm{~m}$ deep. The mill can process up to 10 tons per hour (20 bales per hour). Once inside the

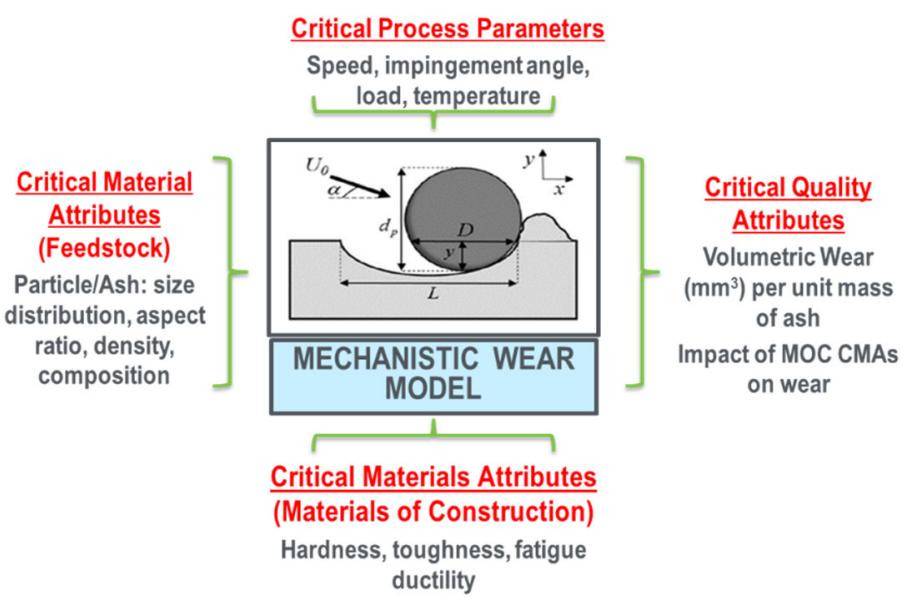

FIGURE 4 Illustration of QbD process for modeling component wear as functions of feedstock CMAs, hammer CMAs, and unit processing parameters, CPPs to wear (CQAs) hammer mill, the corn stover is assumed to congregate in a region near the outer periphery of the drum until it is of sufficiently small size to pass through a sizing screen along the bottom of the drum, where it drops onto a conveyor belt that transports the stover to secondary grinder the brings the material down to sizes in the 2-4 mm size. 


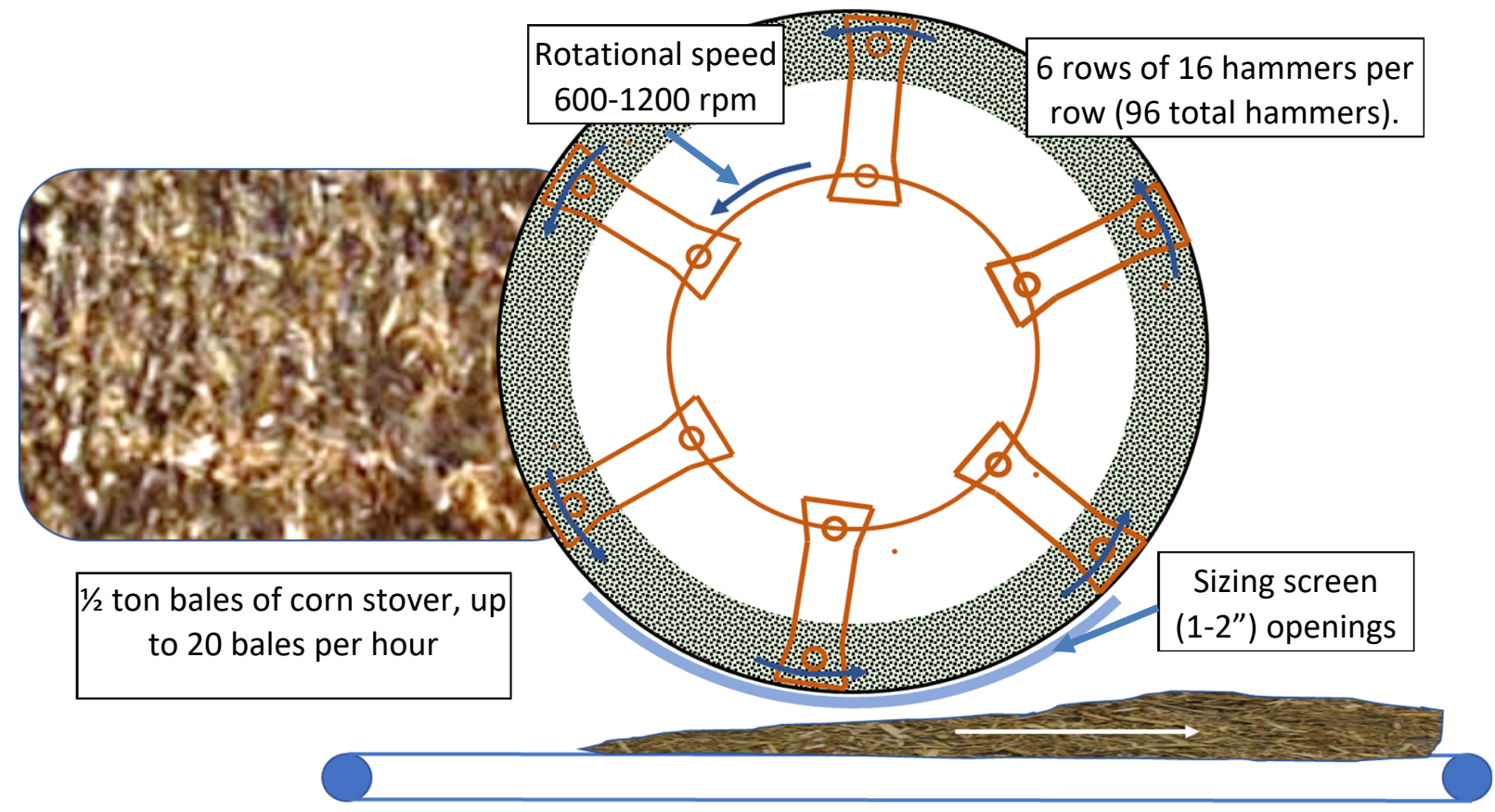

FIGURE 5 Illustration of the Vermeer Stage 1 hammer mill used to grind bales into loose feedstock.

Figure 6 shows a photo of a used stage 1 hammer. The hammers are approximately $25 \mathrm{~cm}$ in length. The hammers are fabricated from a low carbon steel heat treated to a hardness of $400 \mathrm{HKN}$ [10]. The hammer is designed to be mounted in four different orientations, thus providing four different corners that can be used to mill the stover before the hammer is discarded. Three of the corners in Figure 6 were worn; the fourth corner is unworn. Details on the mechanical properties (composition, hardness, fatigue ductility) required to calculate the volumetric wear rate (eqs. 1-3) of the steel used in the stage 1 hammers are presented in reference 10.

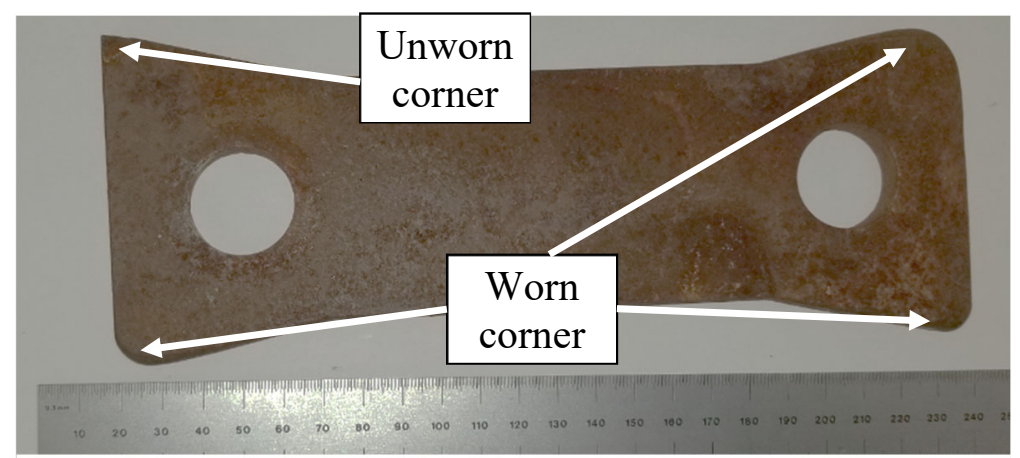

FIGURE 6 Photo of a used stage 1 hammer. 
The process formulated to calculate the wear and in particular the change in shape of the cutting corners of the hammer is illustrated in Figure 7, which shows a small volume, $\Delta V\left(\mathrm{~m}^{3}\right)$, of material eroded on the leading surface of the hammer between $r$ and $r+\Delta r$.

Mathematically, $\Delta \mathrm{V}$ is the product of the wear rate $\Delta \mathrm{QT}_{\mathrm{T}}$ (eq.1) that is a function of radial position, and the mass of particles that impact the leading face per revolution of the hammer $(\Delta \mathrm{m})$ :

$$
\Delta V=\Delta Q * \Delta m
$$

where:

$\Delta \mathrm{V} \quad$ volume eroded per revolution of the hammer $\left(\mathrm{m}^{3} / \mathrm{rev}\right)$

$\Delta \mathrm{Q}$ particle erosion wear rate $\left(\mathrm{m}^{3} / \mathrm{kg}_{\text {ash }}\right)-$ Ben-Ami model (eqs. 1-3)

$\Delta \mathrm{m} \quad$ mass of particles that impact the leading edge of the hammer between $r$ and $r+\Delta r$

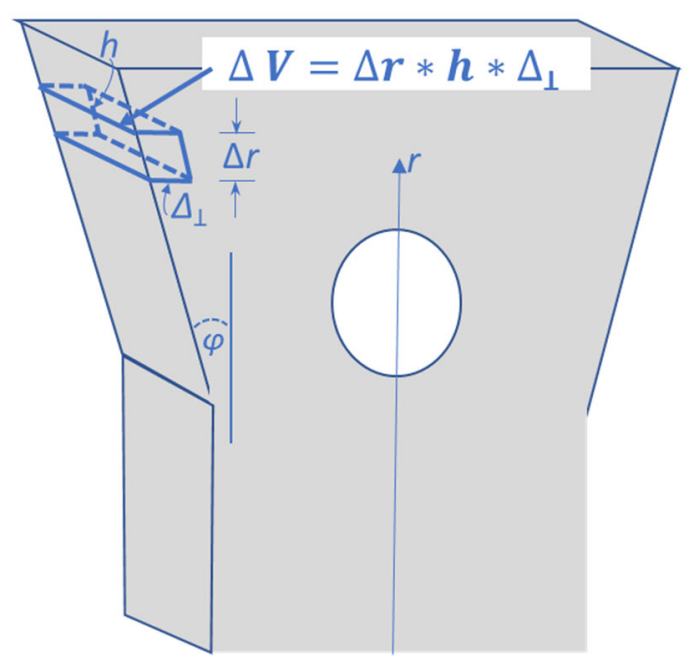

FIGURE 7 Schematic of incremental wear volume on a stage 1 hammer.

The mass of inorganic particles, $\Delta \mathrm{m}$ is given as the product of the particle density $\rho(\mathrm{r})$ and the cylindrical volume swept by the leading face during 1 revolution of the, $\Delta v$ :

$$
\Delta m=\rho(r) * \Delta v
$$

where

$$
\Delta v=2 \pi * h * r * \Delta r
$$

resulting in

$$
\Delta m=\rho(r) * 2 \pi * h * r * \Delta r
$$

substituting eq. 8 into eq. 4 yields

$$
\Delta V=\Delta Q * \rho(r) * 2 \pi * h * r * \Delta r
$$

where:

h hammer width $(\mathrm{m})(0.01 \mathrm{~m})$

$\mathrm{r} \quad$ radial position measured from center of hammer mill (m) 
Noting in Figure 7 that $\Delta \mathrm{V}$ is equivalent to the volume of material eroded from the front face of the hammer, one sees that:

$$
\Delta V=\Delta r * h * \Delta_{\perp}
$$

where $\Delta_{\perp}$ is the distance eroded tangent to the hammer, by the particles; $\Delta_{\perp}$ the variable selected to compare against the experimental shape of the worn corners of the hammers.

Equating eq. 10 to eq. 9 and rearranging terms, one arrives at the following relationship for $\Delta_{\perp}$ :

$$
\Delta_{\perp}=\Delta Q * \rho(r) * 2 \pi * r
$$




\section{RESULTS AND DISCUSSIONS}

The next logical step would be to calculate the weight loss of the hammer for a given set of conditions by integrating eq. 9 along the radial position and dividing the volumetric loss by the density of the hammer material. However, changes in project direction precluded this aspect ${ }^{2}$ and weight loss measurements were not available to compare predicted weight loss against measured weight loss. Rather, we applied predicted values of $\Delta_{\perp}$ against measured hammer shapes and used this to validate the 'workable' model.

Solutions to eq. 11 requires knowledge of the density, $\rho$, which is determined by the feed rate of bales into the hammer mill, the average residence time of particles in the mill, the ash content of the feedstock, and how the ash is distributed within the hammer drum - i.e., the radial distribution of particles. Six distributions were considered/assumed for this study:

Case 1: inorganic particles are uniformly distributed in the mill drum (assumed to be $1 \mathrm{~m}$ in diameter $\times 1.5 \mathrm{~m}$ in length)

$\rho(\mathrm{r})=\mathrm{C}$ for $0<\mathrm{r}<\mathrm{r}_{0}$

Case 2: inorganic particles are uniformly distributed in a peripheral region near the outer diameter between $r=r_{i}$, and $r=r_{0}$ of the drum:

$\rho(\mathrm{r})=0$ for $\mathrm{r}<\mathrm{ri}$

$\rho(\mathrm{r})=\mathrm{C}$ for $\mathrm{r}_{\mathrm{i}}<\mathrm{r}<\mathrm{r}_{0}$

Case 3: inorganic particles are linearly distributed with radial position between $r=0$, and $r=$ ro:

$\rho(\mathrm{r})=\mathrm{A} * \mathrm{r}$ for $0<\mathrm{r}<\mathrm{r}_{0}$

Case 4: inorganic particles are linearly distributed with radial position between $r=r_{i}$, and $r=$ ro: $\rho(\mathrm{r})=\mathrm{A}^{*} \mathrm{r}+\mathrm{C}$ for $\mathrm{r}_{\mathrm{i}}<\mathrm{r}<\mathrm{r}_{0}$

Case 5: inorganic particles have a cubic distribution with radial position between $r=r_{i}$, and $r$ $=\mathrm{r}_{0}$ : $\rho(r)=A * r^{3}+C$ for $r_{i}<r<r_{0}$

Case 6: inorganic particles exhibit an exponential increase with radial position between $r=r_{i}$, and $r=r_{0}$ : $\rho(r)=A e^{\lambda r}+C$ for $r_{i}<r<r_{0}$

The coefficients $\mathrm{A}$ and $\mathrm{C}$ were determined by applying the following boundary conditions:

$\mathrm{BC}$ 1: Total mass in the rotating mill is equal to $\mathrm{FR} * \mathrm{AC} * \tau$

$\mathrm{FR}=$ Feed rate $\left(\mathrm{kg}_{\text {feedstock }} / \mathrm{hr}\right)-1,15,10 \mathrm{sec}$, where:

$\mathrm{AC}=$ Ash content fraction

$\mathrm{T}=$ residence time $(\mathrm{sec}-1,5$, or $10 \mathrm{sec})$

BC 2: For cases $4 \& 5$; the density, $\rho\left(r_{i}\right)$ is equal to zero:

2 The original plan was to validate weight loss of hammers subjected to predetermined quantities of feedstock; however the focus of the project changed from hammermilling to knifemilling operations, and the weight loss study was eliminated. 
Table 1 summarizes the density distributions subject to the following boundary conditions, while Figure 8 shows the density distributions as a function of radial position. The ash density ranges from lows of approximately $0.5 \mathrm{~kg} / \mathrm{m}^{3}$ to $9 \mathrm{~kg} / \mathrm{m}^{3}$ for the exponential distribution at the outer periphery of the milling drum.

Using the density distributions in Table 1 (and Figure 8), the wear, $\Delta_{\perp}$, tangential to the hammer can be determined using eq. 11. Results for the tangential wear due to erosion are shown in Figure 9. These results were determined using the operating parameters given in Table 2. Details on the hammer properties (hardness, toughness, fatigue ductility) are presented in ref. 10.

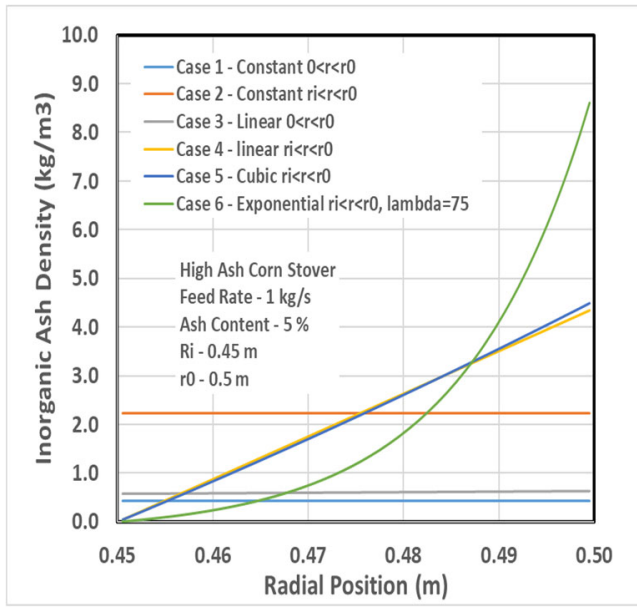

FIGURE 8 Radial distribution of inorganic particle density for a feed rate of $1 \mathrm{~kg} / \mathrm{sec}$ and ash content of $5 \%$.

TABLE 1 Case 1-6 Density Assumptions

\begin{tabular}{|c|c|c|c|c|c|}
\hline Case & Equation & Units & Region & A & C \\
\hline 1 & $\rho(r)=C$ & $\left(\mathrm{~kg}_{\text {ash }} / \mathrm{m}^{3}\right)$ & $0<r<r_{0}$ & 0 & $\mathrm{FR}^{*} \mathrm{~T}^{*} \mathrm{AC} /\left(\pi \mathrm{r}_{0}{ }^{2} * \mathrm{~L}\right)$ \\
\hline 2 & $\begin{array}{l}\rho(r)=0 \\
\rho(r)=C\end{array}$ & $\left(\mathrm{~kg}_{\mathrm{ash}} / \mathrm{m}^{3}\right)$ & $\begin{array}{l}0<r<r_{i} \\
r_{i}<r<r_{0}\end{array}$ & 0 & $\begin{array}{c}0 \\
F R^{*} \tau^{*} A C /\left(\pi^{*} L^{*}\left(r_{0}^{2}-r_{i}^{2}\right)\right)\end{array}$ \\
\hline 3 & $\rho(r)=A r$ & $\left(\mathrm{~kg}_{\text {ash }} / \mathrm{m}^{3}\right)$ & $0<r<r_{0}$ & $3^{*} \mathrm{FR}{ }^{*} \mathrm{\tau}^{*} \mathrm{AC} /\left(2 \pi^{*} \mathrm{~L}^{*} \mathrm{r}_{0}{ }^{3}\right)$ & 0 \\
\hline 4 & $\begin{array}{c}\rho(r)=0 \\
\rho(r)=A r+C\end{array}$ & $\left(\mathrm{~kg}_{\text {ash }} / \mathrm{m}^{3}\right)$ & $\begin{array}{l}0<r<r_{i} \\
r_{i}<r<r_{0}\end{array}$ & $\begin{array}{c}0 \\
\left(F R^{*} \tau^{*} A C\right) /\left(2 \pi^{*} L^{*}\left(\left(\left(r_{0}{ }^{3}-r_{i}^{3}\right) / 3\right)+\left(r_{i}^{*}\left(r_{i}^{2}-r_{0}{ }^{2}\right) / 2\right)\right)\right)\end{array}$ & $\begin{array}{c}0 \\
-A^{*} r_{i}\end{array}$ \\
\hline 5 & $\begin{array}{c}\rho(r)=0 \\
\rho(r)=A^{3}+C\end{array}$ & $\left(\mathrm{~kg}_{\text {ash }} / \mathrm{m}^{3}\right)$ & $\begin{array}{l}0<r<r_{i} \\
r_{i}<r<r_{0}\end{array}$ & $\begin{array}{c}0 \\
\left(F R^{*} \tau^{*} A C\right) /\left(2 \pi^{*} L^{*}\left(\left(r_{0}^{5} / 5-r_{i}^{3} r_{0}{ }^{2} / 2\right)-\left(r_{i}^{5} / 5-r_{i}^{5} / 2\right)\right)\right)\end{array}$ & $\begin{array}{c}0 \\
-A * r_{i}^{3} \\
\end{array}$ \\
\hline 6 & $\begin{array}{c}\rho(r)=0 \\
\rho(r)=A e^{\lambda r}+C\end{array}$ & $\left(\mathrm{~kg}_{\text {ash }} / \mathrm{m}^{3}\right)$ & $\begin{array}{l}1<r<r_{i} \\
r_{i}<r<r_{0}\end{array}$ & $\begin{array}{c}0 \\
\left(F R^{*} \tau^{*} A C\right) /\left(2 \pi^{*} L^{*}\left[\left[e^{\lambda r 0} *\left(\left(\lambda r_{0}-1\right) / \lambda^{2}\right)-e^{\lambda r i} r_{0}^{2} / 2\right]-\left[e^{\lambda r i} *\left(\left(\lambda r_{i}-1\right) / \lambda^{2}\right)-e^{\lambda r i} r_{i}^{2} / 2\right]\right]\right.\end{array}$ & $\begin{array}{c}0 \\
-A e^{\lambda r i}\end{array}$ \\
\hline mill & length $(1.5 \mathrm{~m})$ & 75 & & & \\
\hline
\end{tabular}

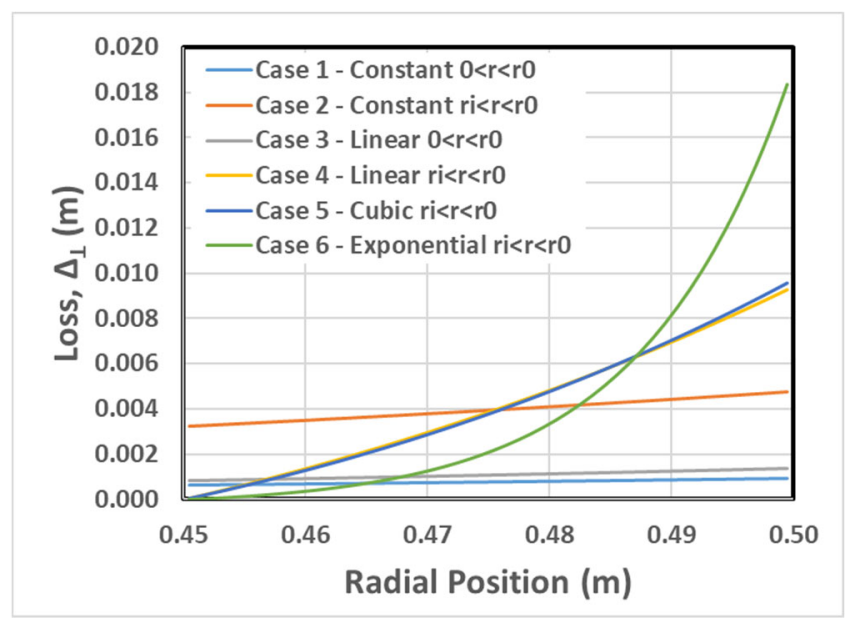

FIGURE 9 Amount of material eroded tangential to hammer face - using process parameters in Table 2 (note the number of revolutions corresponds to 24 hours of operation). 
TABLE 2 Model Parameters

\begin{tabular}{|c|c|c|c|c|c|}
\hline Parameter & Value & Parameter & Value & Parameter & Value \\
\hline Outer Radius of Milling Drum, $r_{0}$ & $0.5 \mathrm{~m}$ & Fedstock Feed Rate, FR & $1 \mathrm{~kg} / \mathrm{s}$ & Inorganic Particle Size, $d_{p}$ & $350 \mu \mathrm{m}$ \\
\hline Inner Radius Inorganic Debris, $r_{i}$ & $0.45 \mathrm{~m}$ & Ash Residence Time, $\tau$ & $10 \mathrm{~s}$ & Particle Shape Factor, $n$ & 0.8 \\
\hline Length of Milling Drum, $L$ & $1.5 \mathrm{~m}$ & Ash Content, AC & $2.5 \%$ & Hammer Thickness, $\mathrm{h}$ & $10 \mathrm{~mm}$ \\
\hline Hammer Face Angle, $\phi$ & $15^{\circ}$ & Hammer Rotational Speed, $\mathbf{N}$ & $900 \mathrm{rpm}$ & Exponential constant, $\lambda$ & 75 \\
\hline Running Time & $24 \mathrm{hrs}$ & Number of Revolutions & 1296000 & & \\
\hline
\end{tabular}

Figure 10 shows the same data (for the cubic and exponential density distributions) plotted alongside a corner of a worn hammer. The red arrows (right side of Figure 10) represent the loss based on a cubic density distribution, while the blue arrows represent an exponential distribution. Although the history of the hammers is not known, and thus comparison of the wear on an absolute basis is not possible, the agreement of the predicted shape (yellow) to the actual shape is encouraging.

The current model assumes the hammer face angle, $\varphi$ (which initially determines the impingement angle of the particles incident on the face), is fixed and does not change due to wear. In reality, wear near the outer tip, particularly near the outer periphery where speeds are greatest, causes the face angle to decrease (swing back to $0^{\circ}$ and become 'negative') resulting in the particle impingement angle changing from $75^{\circ}$ initially, to $90^{\circ}$, then going back down to values near $0^{\circ}$. Further improvements in the ability to replicate the shape of the worn hammer surfaces could be realized by coupling changes in the effective impingement angle, $\varphi$, to recession (wear) of the leading edge, but that is left for a later date should guidance be provided.

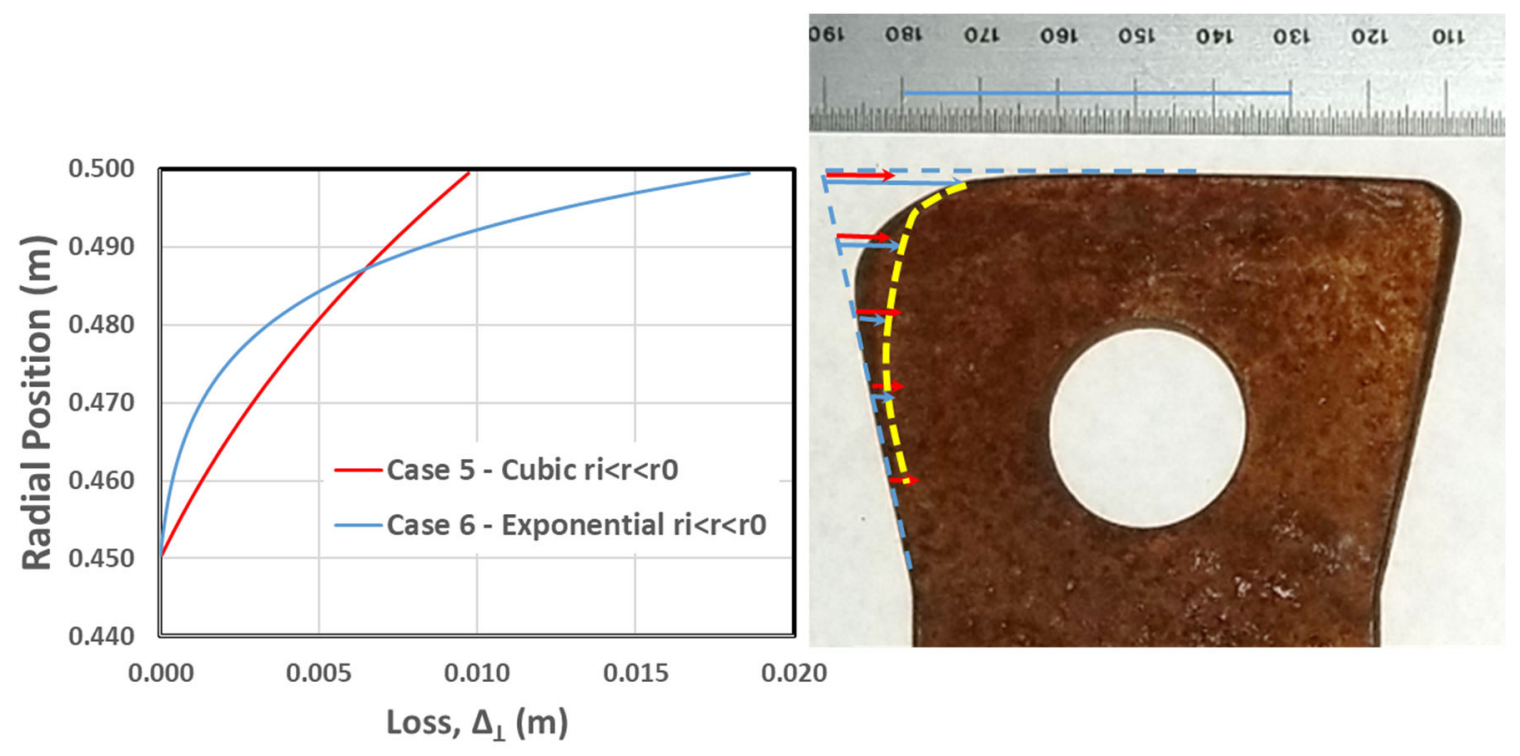

FIGURE 10 Comparison of predicted shape with actual shape of a worn. Yellow line (right) illustrates projected shape for the exponential particle density distribution. 
Application of QbD Model to Hammer Design The treatment described above can provide insight on the impact of design parameters of a hammer mill on hammer durability and performance. Several examples are presented below to illustrate the application of the treatment to predict the impact of different design considerations:

- Impact of hammer design (hammer face angle): The stage 1 hammer is manufactured with a preset face angle, $\varphi$. This angle determines the impingement angle, and thus the wear rates $\left(\Delta \mathrm{Q}_{\mathrm{C}}, \Delta \mathrm{Q}_{\mathrm{D}}\right.$, and $\left.\Delta \mathrm{Q}_{\mathrm{T}}\right)$ and tangential wear of the leading hammer face, $\Delta_{\perp}$. Table 3 shows an example of the application of eq. 11 to optimize/minimize the tangential recession of a hammer using the conditions specified in Table 2 for the low carbon steel alloy used for the Stage 1 hammers. The data represent 24 hours of running at the specified conditions.

TABLE 3 Effect of Hammer Face Angle on Hammer Face Recession

\begin{tabular}{|c|c|}
\hline Face Angle $\boldsymbol{\phi}$ (deg) & Hammer Recession $\boldsymbol{\Delta}_{\perp} \mathbf{( m m )}$ \\
\hline 0 & 18 \\
\hline 15 & 18 \\
\hline 30 & 18 \\
\hline 45 & 16 \\
\hline 60 & 13 \\
\hline 75 & 8 \\
\hline
\end{tabular}

- Impact of rotational speed on hammer wear: The baseline calculations above assumed a rotational speed of $900 \mathrm{rpm}$. Keeping all other parameters constant, eq. $11 \mathrm{can}$ be used to determine the impact of changing the rotational speed. Keep in mind, the feed rate is the same $(1 \mathrm{~kg} / \mathrm{sec})$ as well as the assumed residence time, $\tau$, which may not be a reasonable assumption. One would expect that the product of FR * $\tau$ should be a constant. Nevertheless, the effect of changing the rotational speed can be evaluated, as shown in Table 4, and as seen, the effect of rotational speed is quite strong due to the strong velocity dependence of $\Delta \mathrm{Q}$ on velocity.

TABLE 4 Effect of Hammer Rotational Speed on Hammer Face Recession

\begin{tabular}{|c|c|}
\hline Rotational Speed $(\mathbf{r p m})$ & Hammer Recession $\boldsymbol{\Delta}_{\mathbf{\perp}} \mathbf{( \mathbf { m m } )}$ \\
\hline 600 & 4 \\
\hline 750 & 9 \\
\hline 900 & 18 \\
\hline 1050 & 33 \\
\hline 1200 & 55 \\
\hline
\end{tabular}


- Impact of material properties on wear and recession: Additional design considerations to consider as potential solutions to mitigate wear and maintain performance involve the selection and treatment/engineering of the materials and alloys used to fabricate the hammers. This is the goal of Task 1 from the start, and the activities under Task 1.3 have culminated in the development of a semi-mechanistic model of erosive wear that predicts wear of hammer components as functions of properties/attributes of the feedstock particles, properties of the hammer materials, and the operating parameters, which are system-dependent. The critical feedstock properties are particle size, particle shape, and particle density (assumed to be $2600 \mathrm{~kg} / \mathrm{m}^{3}-\mathrm{SiO}_{2}$ ), while the critical material include hardness $(H)$, fracture toughness $(R)$, and fatigue ductility $\left(\epsilon_{f} \& n\right)$.

An example of sensitivity of the predicted recession, $\Delta_{\perp}$, on the mechanical properties on the hammer material is shown in Table 5, which presents results from eq. 11 for different values of fatigue ductility, $\epsilon_{\mathrm{f}}(0.01$ to 1.0$)$, hardness ( 4 to $\left.12 \mathrm{GPa}\right)$, and fracture toughness $\left(5\right.$ to $\left.50 \mathrm{~kJ} / \mathrm{m}^{2}\right)$.

TABLE 5 Predicted Hammer Recession, $\Delta \mathbf{\perp}(\mathrm{m})$, for Different Material Property Combinations

\begin{tabular}{|c|c|c|c|c|c|c|c|c|c|c|c|c|}
\hline \multirow{3}{*}{$\begin{array}{c}\text { Fracture } \\
\text { Toughness }\end{array}$} & \multicolumn{3}{|c|}{$\epsilon=0.01$} & \multicolumn{3}{|c|}{$\epsilon=0.1$} & \multicolumn{3}{|c|}{$\epsilon=0.5$} & \multicolumn{3}{|c|}{$\epsilon=1.0$} \\
\hline & \multicolumn{3}{|c|}{ Hardness } & & & & & & & & & \\
\hline & $4 \mathrm{GPa}$ & $8 \mathrm{GPa}$ & $12 \mathrm{GPa}$ & $4 \mathrm{GPa}$ & $8 \mathrm{GPa}$ & $12 \mathrm{GPa}$ & $4 \mathrm{GPa}$ & $8 \mathrm{GPa}$ & $12 \mathrm{GPa}$ & $4 \mathrm{GPa}$ & $8 \mathrm{GPa}$ & $12 \mathrm{GPa}$ \\
\hline $5 \mathrm{~kJ} / \mathrm{m}^{2}$ & 111.598 & 67.908 & 50.783 & 2.408 & 1.465 & 1.096 & 0.168 & 0.102 & 0.077 & 0.056 & 0.034 & 0.025 \\
\hline $20 \mathrm{~kJ} / \mathrm{m} 2$ & 42.288 & 25.732 & 19.243 & 0.913 & 0.555 & 0.415 & 0.064 & 0.039 & 0.029 & 0.021 & 0.013 & 0.010 \\
\hline $30 \mathrm{~kJ} / \mathrm{m} 2$ & 31.839 & 19.374 & 14.488 & 0.687 & 0.418 & 0.313 & 0.048 & 0.029 & 0.022 & 0.016 & 0.010 & 0.007 \\
\hline $40 \mathrm{~kJ} / \mathrm{m} 2$ & 26.032 & 15.840 & 11.846 & 0.562 & 0.342 & 0.256 & 0.040 & 0.024 & 0.018 & 0.013 & 0.008 & 0.006 \\
\hline $50 \mathrm{~kJ} / \mathrm{m} 2$ & 22.267 & 13.549 & 10.133 & 0.481 & 0.292 & 0.219 & 0.034 & 0.021 & 0.015 & 0.012 & 0.007 & 0.005 \\
\hline
\end{tabular}

The baseline condition for the prototypical hammer used in the Stage 1 hammer mill is shaded in blue ( $40 \mathrm{HKN}, 20-30 \mathrm{~kJ} / \mathrm{m}^{2}$, and a fatigue coefficient of 1.1). As seen in the table, there is not much room/opportunity for improvement. Harder and tougher materials will help to reduce wear/recession, but one must maintain fatigue ductility - which may present a challenge. Specifying material properties is one thing; identifying materials and material processing procedures (heat treating and surface treatments) that provide the desired properties is another. 


\section{CONCLUSION}

The objective of Task 1.3 was the development of a semi-mechanistic model of wear (erosive wear) to predict wear and degradation of hammers used in the comminution of biomass feedstocks into forms compatible with conversion processes. The task included three milestones to develop a QbD approach to predict wear attributes as functions of feedstock and hammer attributes, and operational process parameters:

- development of physical and mathematical models to predict wear,

- validation of the model against labscale simulation of erosive wear, and

- development of a workable model, validated against wear of hammers used in an operating commercial hammer mill.

The first milestone was completed and reported out in ref 5 (FY19 Q2); the second milestone was completed in FY20, Q2 (ref (10); and the current report completes the third milestone on a workable model of erosive wear.

Results of all three milestones are being applied in collaboration with Task 1.1 to develop material specifications on hardness, toughness, and fatigue ductility for different applications, and to identify material processes can provide the required properties. Two approaches under consideration involve boriding near surface regions - one involves nickel boriding, while the second involves iron boriding. Alternative processes involving tool steels and advanced heat treating processes such as laser hardening are also under consideration. 


\section{FUTURE DIRECTIONS}

With proper consideration of the hammer shape, one can further model the local contact stresses imparted by the hammer to the feedstock and use this information to provide determine if sufficient forces are being applied to fracture the feedstock into smaller sizes.

Future activities will focus on transitioning to knife milling operations. Initial activities will include:

- $\quad$ literature searches to identify the physical phenomena associated with knife milling operations and, if needed, develop semi-mechanistic models of abrasive wear phenomena involved in knife milling

- analysis of conceptual knife mills under consideration for biomass processing of corn stover and pine feedstocks to identify critical process parameters. 


\section{REFERENCES}

[1] Office of Energy and Efficiency \& Renewable Energy, 2020,"Bioenergy Technologies.” Available at https://www.energy.gov/eere/bioenergy.

[2] Julie Baruah, Bikash Kar Nath, Ritika Sharma, Sachin Kumar, Ramesh Chandra Deka, Deben Chandra Baruah, and Eeshan Kalita, 2018, "Recent Trends in the Pretreatment of Lignocellulosic Biomass for Value-Added Products," Frontiers in Energy Research 6, article 141. Available at www.frontiersin.org.

[3] Adepu Kiran Kumar and Shaishav Sharma, 2017, "Recent Updates on Different Methods of Pretreatment of Lignocellulosic Feedstocks: A Review," Bioresources and Bioprocessing 4, article 7. DOI 10.1186/s40643-017-0137-9.

[4] Solange Mussatto, ed., 2016, Biomass Fractionation Technologies for a Lignocellulosic Feedstock Based Biorefinery, Elsevier. ISBN: 978-0-12-802323-5.

[5] George Fenske and Oyelayo Ajayi, "An Analytical Model of Erosive Wear of Biomass Comminution Components", Argonne National Laboratory Report - ANL/AMD -20/1, October 2020.

[6] E. Wolfrum, 2019, "Hammer mill," DOE Bioenergy Technologies Office 2019 Project Peer Review, Feedstock-Conversion Interface Consortium (FY2018), Denver, CO, March.

[7] J. Qu, W. Li, and J. Keiser, 2018, "ORNL Contribution to FY18 Q3 Quarterly Progress Report for the FCIC Process Integration Project," WBS 2.2.1.50x.

[8] George Fenske and Oyelayo Ajayi, 2018, “ANL Contribution to FY18 Q4 Quarterly Progress Report for the FCIC Process Integration Project,” WBS 2.2.1.50x.

[9] Y. Ben-Ami, A. Uzi, and A. Levy, 2016, "Modelling the Particles Impingement Angle to Produce Maximum Erosion," Powder Technology 301: 1032-1043.

[10] G. Fenske and O. Ajayi, "Task 1, Materials of Construction Task 1.3, Mechanics of Wear FCIC Milestone Report for FY20, Q2, Argonne National Laboratory, Lemont, IL.

[11] Kyungjun Lee, Sougata Roy, Ercan Cakmak, Jeffrey A. Lacey, Thomas R. Watkins, Harry M. Meyer, Vicki S. Thompson, James R. Keiser, and Jun Qu, 2020, "CompositionPreserving Extraction and Characterization of Biomass Extrinsic and Intrinsic Inorganic Compounds," ACS Sustainable Chemical Engineering 8: 1599-1610. 



\section{Argonne}

\section{Applied Materials Division}

Argonne National Laboratory

9700 South Cass Avenue, Bldg. 362

Lemont, IL 60439-4832

www.anl.gov 